\title{
HUGO RODRÍGUEZ ALCALÁ E A CRÍTICA LITERÁRIA PARAGUAIA: PRESENÇAS-AUSÊNCIAS
}

\author{
HUGO RODRÍGUEZ ALCALÁ AND PARAGUAYAN \\ LITERARY CRITICISM: PRESENCES-ABSENCES
}

\author{
Débora Cota ${ }^{1}$ \\ [https://orcid.org/0000-0001-5920-6896] \\ DOI: 10.30612/raido.v15i38.14737
}

\begin{abstract}
RESUMO: O estudo volta-se para a produçáo crítica do paraguaio Hugo Rodríguez Alcalá (1917-2007) que pertenceu à geraçăo de 40 mas viveu exilado nos Estados Unidos durante aproximadamente quatro décadas. Parte de sua produçāo ensaística está concentrada em dois livros: Siete ensayos (1987) e La incógnita del Paraguay y otros ensayos (1987) lançados em Assunçăo depois de seu retorno ao país. RodríguezAlcalá é também autor de História de la literatura paraguaya (1970 e 2000) e figura central para se pensar o campo intelectual paraguaio e seus diálogos com a América Latina e o exterior. Tais diálogos e contribuiçóes sáo analisados aqui a partir de sua condiçâo de intelectual exilado (SAID, 2009), certa perspectiva latino-americanista e, especialmente, as consideraçôes em torno da "presença/ausência da literatura paraguaia" que recoloca as especificidades da constituiçăo do campo (BOURDIEU, 1992) literário no Paraguai e seus processos de divulgaçăo e legitimaçăo.
\end{abstract}

Palavras-chave: Crítica literária; literatura paraguaia; campo literário.

ABSTRACT: The study focused on the critical production of Paraguayan Hugo Rodríguez Alcalá (1917-2007) who belonged to the generation of 40 but lived in exile in the United States for approximately four decades. Part of his essay production is concentrated in two books: Siete ensayos (1987) and La incógnita del Paraguay y otros ensayos (1987) released in Asunción after his return to the country. Rodríguez-Alcalá is also the author of História de la literatura paraguaya (1970 and 2000) and a central figure for thinking about the Paraguayan intellectual field and its dialogues with Latin America and abroad. Such dialogues and contributions are analyzed here from his status as an exiled intellectual (SAID, 2009), a latin-americanist perspective and, especially, the considerations about the "presence/absence of Paraguayan literature" that replaces the specificities of the constitution of the literary field (BOURDIEU, 1992) in Paraguay and its processes of dissemination and legitimation.

Keywords: Literary criticism; Paraguayan literature; literary field.

Nâo se tem muita notícia sobre crítica literária paraguaia. Apesar de que muitos escritores se dedicaram também ao estudo da literatura e da cultura daquele país, suas

1 Universidade Federal da Integraçâo Latino-americana (UNILA). 
criaçôes literárias (romances, poesias, contos...) tendem sempre ser mais conhecidas do que seus trabalhos críticos, ensaísticos. Apenas um nome aponta neste desértico cenário, o de Hugo Rodríguez Alcalá. No entanto, o crítico, mas também renomado escritor, se insere no campo intelectual paraguaio de maneira singular, sua crítica é em grande parte produzida durante os quase quarenta anos que viveu nos Estados Unidos depois de se exilar naquele país.

Neste estudo esboça-se uma primeira aproximaçâo à produçăo crítica do autor evidenciando um trabalho de cunho hispanista ou latino-americanista, muito preocupada em dar conta da constituiçăo de uma literatura paraguaia em contraste a certas depreciaçóes acerca da existência de uma literatura no país. Esta crítica no exílio, portanto, em trânsito, revela muito sobre o diálogo deste país com o exterior e traz à tona as especificidades da constituiçăo do campo (BOURDIEU, 1992) literário no Paraguai e seus processos de divulgaçâo e legitimaçâo.

Hugo Rodríguez Alcalá se formou em Direito e Ciências Sociais em Assunçâo (1943) e em Filosofia e Letras nos Estados Unidos (1953). Escreveu cerca de quarenta livros e entre eles muitos estudos importantes sobre a literatura paraguaia e hispano-americana, como o dedicado a Juan Rulfo. De acordo com David William Foster (1975), Alcalá escreve o primeiro ensaio de alcance internacional sobre os contos de Roa Bastos e um dos primeiros estudos sobre Hijo de hombre. Mas, além de crítico, é um grande poeta. Seu nome encontra-se entre o de importantes poetas paraguaios ${ }^{2}$.

O crítico foi professor de literatura em diversas universidades americanas e fez parte da comissâo editorial de importantes revistas estrangeiras como Hispanic Review, Revista Iberoamericana, Hispanic Journal, Letras de Buenos Aires e na capital do México foi diretor do Centro de Estudios de la Universidad de California (19721974). Em Assunçăo, após o seu retorno, foi presidente da Academia Paraguaya de la Lengua Española (1989-1994) e fundador do Taller Cuento Breve, de onde despontaram importantes escritores paraguaios.

Nâo há muita notícia sobre seu exílio, mas o ano em que chegou nos EUA, 1947, é o ano de início da Guerra Civil que, ocasionou, como aponta Méndez-Faith (1985, p.3) uma política imperante de repressăo e censura no Paraguai. Ainda segundo a autora (MENDÉZ-FAITH, 1985, p. 3), o país sofreu uma "drenagem intelectual" nos anos posteriores à Guerra do Chaco (1932-1935), guerra na qual Rodríguez Alcalá esteve presente, e especialmente a partir da Guerra Civil de 1947.

A sinuosa história das guerras do Paraguai e sua relaçâo com o meio social e cultural é ponto crucial na abordagem da literatura do país pois está relacionada a mudanças paradigmáticas na organizaçăo do campo intelectual e cultural ao determinar um cenário de instabilidade social e de fuga de produtores culturais e de intelectuais. De acordo com Carla Daniela Benisz já foram feitas algumas correçôes ao modelo de campo intelectual e literário de Pierre Bourdieu considerando o contexto latino-americano:

Si el campo intelectual francés del modelo bourdesiano (Bourdieu, 1995 y 2002) es contenido en una configuración nacional (ésta es la "limitación" que le observan

2 Sobre a poesia do autor, Juan Manuel Marcos escreveu: La poética de Hugo Rodríguez Alcalá: técnica y estilo, obra publicada em Assunçâo, em 1997. Josefina Plá também dedicou alguns textos à sua poesia. 
Atamirano \& Sarlo, 1983, pág. 85), esa configuración, en cambio, no podría contener ni explicar por sí misma las características del campo latinoamericano, que se vincula con espacios consagratorios y de difusión externos. Esto se relaciona con otro reparo, que le realiza Silvia Sigal (2002), a la perspectiva de Bourdieu a la hora de aplicarla en América Latina. La autora explica que en un campo como el latinoamericano, además del campo de poder, otra fuerza externa a su especificidad influye sobre las instancias y los valores de consagración: los centros metropolitanos de producción cultural e intelectual. (BENISZ, 2018, p.611-612)

As consideraçōes de Benisz partem justamente de seu estudo sobre a literatura paraguaia, especialmente sobre as polêmicas pós-stronistas que envolveram o meio intelectual daquele país e dâo destaque a dois importantes aspectos que incidem na abordagem da crítica de Rodríguez Alcalá: a concretizaçâo de um espaço consagratório e de difusâo da literatura latino-americana e paraguaia no exterior; e a importância dos centros metropolitanos de produçáo cultural e intelectual como Buenos Aires, para a existência de tal literatura.

Este trabalho, mais preocupado com a contribuiçâo do crítico à criaçăo deste espaço consagratório e de difusâo da literatura paraguaia para além de suas fronteiras, toma como ponto de partida duas importantes coletâneas críticas organizadas em Assunçâo, depois do retorno de Rodríguez Alcalá a seu país, nos anos de 1980, e sua Historia de la Literatura Paraguaia, dos anos de 1970. As duas coletâneas críticas, La incógnita del Paraguay e Quince ensayos săo de 1987 e recolhem artigos inéditos no Paraguai mas, publicados em várias partes do mundo como Madri, Nova Iorque, Buenos Aires e México, nos anos 60, 70 e início dos 80.

O primeiro aspecto destacável das coletâneas é certa perspectiva hispano-americanista ou hispanista que o crítico apresenta na escolha dos autores estudados. Antes de adentrarmos neste tema, é bom também registrar que Rodríguez Alcalá năo escreve apenas sobre literatura, mas também sobre filosofia, sobretudo, sobre filósofos e intelectuais espanhóis como Miguel de Unamuno e Ortega y Gasset. Entre os autores hispano-americanos sobre os quais se debruça estăo Juan Rulfo, Jorge Luis Borges, Rómulo Gallegos, José Emilio Pacheco, Ricardo Güiraldes, e até o ensaísta e latino-americanista Pedro Henríquez Ureña. Este perfil é um importante traço de uma crítica tecida por um latino-americano fora de seu país de origem e também fora da América Latina. Há uma visấo, se năo em conjunto da regiăo, pelo menos mais ampla, comum a quem está no exterior, a quem saiu e vê desde fora sua regiăo de proveniência.

Por outro lado, trata-se de uma crítica vinculada aos estudos hispânicos estadunidenses pois se origina dentro das academias localizadas no país. O hispanismo estadunidense passava, na época, por mudanças significativas, abrindo, conforme David T. Gies (2001, p. 495), seu currículo moderno de estudos hispânicos que era muito peninsular, para a cultura latino-americana e a cultura latina nos EUA. Isto explica, em grande parte também, a perspectiva hispanista e năo latino-americanista de Hugo Rodríguez Alcalá, ou seja, o foco, sobretudo, em escritores e pensadores espanhóis e hispano-americanos. Sobre Rodríguez Alcalá Eduardo Neal-Silva, professor emérito da University of Wisconsin afirma: "Al descubrir la realidad norteamericana, empezó a perfilarse en su mente con mayor nitidez el ser de la comunidad hispánica, vista ahora 
no sólo como un conjunto de naciones americanas sino como una colectividad aún mayor, en la cual le cabía a España ser la raíz de origen" (NEAL-SILVA, 1982).

É válido esclarecer que năo falta na produçăo crítica do autor estudos sobre autores estrangeiros, europeus ou mesmo autores norte-americanos como por exemplo, Jorge Guillén, Elio Vittorini, Williams Carlos Williams, entre outros. Mas, năo foi encontrado até o momento nenhum estudo de sua autoria sobre literatura brasileira e o uso da expressâo literatura latino-americana, pelo menos nas duas coletâneas, é ausente. Rodríguez Alcalá inclusive se utiliza de termos como América ou América española ou Nuevo Mundo para se referir à América Latina. Tais ausências denunciam a năo existência de vínculo com o pensamento latino-americanista posto em prática por intelectuais como o uruguaio Ángel Rama e o peruano Antonio Cornejo Polar naquele momento.

A única referência que o aproxima ao integracionismo latino-americano, nas coletâneas em questâo, é o estudo sobre Pedro Henríquez Ureña. Este autor, que também viveu nos EUA, foi um precursor, como sabemos, de um pensamento integracionista que considerava a cultura brasileira e um dos pensadores latino-americanos, ao lado de José Luis Romero (a quem Rodríguez Alcalá também dedicou algumas páginas), de grande destaque nos anos de 1940. O texto de Rodríguez Alcalá faz mençâo ao desejo de Ureña por expressóes originais, por uma "auténtica expresión de América" com relaçăo às produçôes artísticas culturais, alcançada, segundo Alcalá, pela nova narrativa, ou seja, pelos escritores do Boom latino-americano: García Márquez, Roa Bastos, Juan Rulfo e Arguedas. Esta seria a principal manifestaçăo de um perfil integracionista em sua perspectiva crítica, observada até o momento.

Por outro lado, como náo poderia deixar de ser, o crítico desenvolveu um grande estudo da literatura de seu país de origem que abarca uma série de textos críticos e uma história da literatura do Paraguai. Além de seus reconhecidos trabalhos sobre Juan Rulfo, os textos sobre Roa Bastos, o alçaram como representante desta literatura no exterior. Portanto, năo é de se estranhar que entre seus textos críticos encontrase um levantamento sobre a repercussăo em torno da polêmica consideraçăo sobre a literatura paraguaia manifestada pelo escritor peruano Luis Alberto Sánchez. Este autor dedica algumas páginas, em 1937, sob o título La incógnita del Paraguay em sua Historia de la literatura americana: desde los orígenes hasta 1936. O artigo Luis Alberto Sánchez y el Paraguay: historia de una incógnita, foi escrito 40 anos depois, para compor um livro de homenagem pelos oitenta anos do escritor peruano, publicado em Madri, em 1983 e dele se depreendem năo apenas a repercussâo da declaraçấo de Sánchez entre a intelectualidade paraguaia mas também a maneira como é entendida a constituiçăo do campo literário paraguaio por Alcalá e a existência de uma literatura do país.

Luis Alberto Sánchez vem ao Paraguai em 1948 devido a um levantamento político em seu país do qual é partidário e que o fará ser perseguido pelo governo local. O escritor peruano recebe a ajuda do embaixador paraguaio em Lima que o envia a Assunçâo. Rodríguez Alcalá fala de algumas particularidades da chegada de Sánchez ao Paraguai mas principalmente adverte sobre o período de recente evasăo da intelectualidade e de escritores do país em decorrência da Guerra Civil, instaurada no ano anterior. Ou seja, adverte que Sánchez nâo teve contato com uma intelectualidade que pudesse ter enriquecido seu conhecimento do país. 
A incógnita do Paraguai vai se mostrando na perspectiva de Rodríguez Alcalá como um desconhecimento do crítico peruano sobre a realidade paraguaia. Cita artistas, pensadores e escritores que nâo săo nomeados nos livros de Sánchez. Inclusive mostra que Sánchez năo mostrou conhecimento sequer do fato de que na década em que chega ao Paraguai se organiza um dos maiores movimentos intelectuais e artísticos do país, com ressonâncias continentais. Movimento que hoje conhecemos como a geraçăo de 40 e que está constituído por nomes como Augusto Roa Bastos, Herib Campos Cervera, Elvio Romero, Josefina Plá, entre outros, além do próprio crítico que é também poeta. O crítico faz uma série de observaçōes e dá exemplos em torno do desconhecimento de Sánchez, como os que se apresentam nas linhas abaixo:

Debe entenderse bien que el ambiente caldeado por las pasiones políticas, la inquietud, la zozobra en que vivía el Paraguay, no le permitieron ni siquiera sospechar que precisamente en la década iniciada en 1940, y no terminada aun cuando llega al país, se había suscitado un importantísimo movimiento intelectual y artístico. Hacia 1940, en efecto, surge una pléyade de escritores y artistas, algunos de los cuales lograron fama continental. Esto ocurría pela primera vez en la historia del Paraguay; nunca antes había surgido un narrador comparable a Roa Bastos; ningún poeta como Hérib Campos Cervera había influido ni iba influir tanto en el Paraguay de antes, de entonces y de después, ningún paraguayo ha ganado como Elvio Romero, parejo renombre de poeta ni le ha superado en fecundidad hasta la fecha. En la década siguiente, entonces ya muy próxima, surgiría otra pléyade acaso tan meritoria como la anterior. Pero esto no podía menos de ser una incógnita para Sánchez en 1948. Todavía hoy sigue siéndolo en el extranjero, aun para especialistas. (RODRÍGUEZ-ALCALÁ, 1987, p. 18)

É importante considerar que em pelo menos dois momentos o crítico procura explicar a "miopia" de Sánchez através de seu desconhecimento da realidade política paraguaia, causa inclusive da ausência de grandes escritores naquele momento, no país. Ou seja, Rodríguez Alcalá tenta chamar a atençăo para a especificidade do campo intelectual paraguaio, que năo deve ser pensado apenas pelo que se encontra no país. Ainda que a miopia é tăo severa que faz com que Sánchez só fale de Roa Bastos em uma publicaçăo dos anos de 1970. Nem a segunda ediçâo de sua Historia de la literatura americana, elaborada cerca de 30 anos depois, contém o nome do mais conhecido escritor paraguaio, segundo o crítico paraguaio.

De modo geral, se arma no texto do crítico paraguaio uma insistência na existência de uma literatura e as limitaçóes impostas pelas guerras sofridas pelo país para o (re) conhecimento desta literatura para além de suas fronteiras e as consequências destes acontecimentos para a configuraçáo do campo intelectual paraguaio. Trata-se, neste sentido, de uma presença/ausência, desta literatura pois ao mesmo tempo que aponta para a existência de tal literatura năo contradiz seu desconhecimento.

Alcalá faz referência ao fato de que já em 1967, em um texto sobre Roa Bastos, ele se preocupava com a polêmica afirmaçâo de Sánchez acerca de um Paraguai ignoto. Mas náo está demais pensar que sua própria Historia de la literatura paraguaya, publicada em 1970, também seja uma resposta a tal provocaçăo. A obra foi publicada primeiramente no México e, no ano seguinte, no Paraguai. Em 1999, ganha a autoria 
também de Dirma Pardo Carugati ${ }^{3}$. O primeiro capítulo intitulado Los siglos coloniales, começa justamente lembrando a negaçăo sobre a existência de uma história literária no Paraguai, que o erudito espanhol Menéndez Pelayo apresenta em Historias de la poesia hispanoamericana (1948).

No Prólogo, o autor já antecipa que insistirá na literatura paraguaia do século XX, século no qual tem início o ensaio, o conto e o romance e é produzida uma importante lírica. Para ele "Los siglos coloniales son, literariamente, un vasto desierto con algunas matas verdeantes sobre la arena estéril." (1970, p. 7) Posteriormente, o autor apresenta de maneira breve as várias ditaduras e guerras pelas quais o país passa a partir da segunda metade do século XIX e que torna impossível a vida intelectual: a ditadura de Gaspar de Francia (1814-1840); a Guerra Grande ou a Guerra contra o Paraguai (1864-1870); e a Guerra do Chaco (1932-1935). Os anos de 1940, apesar de marcados pela Guerra Civil de 1937 e o início do que seria a ditadura de Alfredo Strossner, ambos acontecimentos năo citados no prólogo de Alcalá, săo saudados como os anos mais frutíferos da literatura, de amadurecimento dos gêneros e de renovaçăo vanguardista na lírica ${ }^{4}$. A história da literatura paraguaia parece terminar nos anos de 1940, justo na geraçăo a qual pertence o próprio crítico e escritor. Enfim, a geraçăo que nos anos de 1960, quando ainda estava sendo escrita a Historia de la literatura paraguaya, era ainda a mais proeminente no país.

A História de la literatura paraguaya tem algumas particularidades. Trata-se de um único volume, em formato de um caderno, dividido em dez breves capítulos. O capítulo um é dedicado aos séculos coloniais mas o dois, no entanto, tratará da ditadura perpétua do Dr. Francia, para somente no três falar do romantismo. Isto năo quer dizer contudo que haverá um capítulo dedicado à Guerra contra o Paraguai ou à Guerra do Chaco ou à ditadura do general Alfredo Strossner. Mas a perspectiva histórica é uma constante. O capítulo cinco, por exemplo, trata apenas do ensaio e da história desde 1915, ou seja, vai falar dos historiadores paraguaios. Por ora também o livro se organiza por escolas literárias, romantismo, modernismo, por ora, por gêneros: ensaio, poesia, narrativa, teatro. Mas, de modo geral, os capítulos sâo desenvolvidos a partir de uma apresentaçáo a partir da biografia e das obras dos autores representantes, sendo ausente análises mais aprofundadas.

A abertura à história, todavia, é menos uma ampliaçâo ao conceito de literatura ou de ficçáo, que um traço de um perfil humanista de formaçăo do crítico. Assim, a literatura e, portanto, a crítica literária, estăo neste limiar da história e da filosofia.E a literatura é literatura, nâo está aberta a outras manifestaçôes que nâo seja a escrita nos gêneros clássicos. Assim sendo, apenas no teatro que veremos manifestaçóes da cultura guarani. $O$ crítico chamará a atençăo para poetas que cultivam o teatro

3 A primeira ediçăo, de 1970, foi publicada por Ediciones De Andrea, no México. E a segunda, pela Ediciones S. M. de Madri, em 1971. As ediçōes comentadas aqui săo a de 1971, editada por Ediciones S. M. de Madri mas publicada pelo Colegio de San José, de Assunçâo; e a de 1999, publicada por El Lector, em Assunçáo. Em 2017, a Historia de la literatura paraguaya ganha uma nova ediçẫo, pela editora Servilibro de Assunçăo.

4 Além dos anos 40 o único período favorável ao desenvolvimento da cultura no país, segundo o autor, será o da independência, logo após a 1811. Nele, a Junta Superior Gubernativa presidida por Fulgencio Yedros, o prócer poeta, cria em 1814 uma Sociedade Patriótica Literaria, uma Academia Militar, uma Biblioteca Pública e considera o desenvolvimento da educaçâo a tarefa central de sua gestâo. (RODRÍGUEZ-ALCALÁ, 1970, p. 7) 
em língua guarani. Apenas no século vinte é que haverá um reflorescimento deste teatro, reflorescimento porque este foi cultivado pelos jesuítas. Trata-se de uma concepção moderna do literário que, como nos lembra Antoine Compagnon (2001, p. 32), se restringe "à prosa romanesca e dramática, e à poesia lírica". Além disso, para Compagnon tal concepçăo de literatura é concebida "em suas relaçóes com a naçăo e com sua história" (2001, p. 33), preocupaçâo que na história da literatura de Alcalá é uma constante.

Com este título, năo há outra história da literatura daquele país. Mais conhecidas săo a História de las Letras Paraguayas (1947), em três volumes, de Carlos R. Centurión que abarca uma produçấo abundante de prosa, poesia, história teatro e periodismo, em espanhol e em guarani. Estăo incluídas nesta história informaçôes sobre instituiçôes culturais e do magistério, públicas e privadas e também informaçôes sobre professores, oradores, políticos, compositores e homens de ciência, entre outros. A obra recebeu algumas críticas especialmente no que se refere a ausência de referências a figuras importantes como: Augusto Roa Bastos, Gabriel Casaccia, Hugo Rodríguez Alcalá, José M. Rivarola Mato e Juan B. Rivarola Mato. Por outro lado, tem-se Literatura paraguaya en el siglo XX, de Josefina Plá, também publicada nos anos de 1970 mas, dedicada especificamente ao século XX. Damián Cabrera, em sua dissertaçâo de mestrado (2016), alerta sobre a carência da pesquisa acadêmica no Paraguai e a escassez da crítica:

A historiografia literária năo passa na maioria das vezes de inventários biográficos, e a crítica literária - tanto acadêmica como jornalística - tem sido mais escassa que a produçăo literária: apenas alguns momentos memoráveis de efervescência, menos periodizados do que a produçáo literária, existentes na maioria das vezes apenas na memória de seus artífices, exposta, às vezes, oralmente. A pesquisa de arquivos é quase nula, uma vez que nâo existe uma academia comprometida com a pesquisa, e muitos arquivos estáo apenas sistematizados, menos ainda digitalizados, muitos deles precários e correndo o risco de se perder para sempre; outros já irremediavelmente perdidos. 0 país sem memória de arquivo é o país onde foram achados toneladas de documentos dos Arquivos do terror: vestígios documentais das ditaduras do Cone Sul, achados no depósito de uma delegacia de polícia: achados mas ainda por descobrir. (CABRERA, 2016, p.43)

As palavras de Cabrera procuram esclarecer a situaçáo dos estudos acadêmicos no Paraguai mas o autor também levanta a hipótese de que muitos estudos partem de "genealogias e inventários" para possivelmente "contradizer a história de uma literatura inexistente" (CABRERA, 2016, p. 43). Rodríguez-Alcalá constrói sua Historia de la literatura paraguaya mostrando que há uma história da literatura no país. Enfim, que há uma literatura. Mas os "inventários" năo param por aí: em La incógnita del Paraguay para retomarmos a coletânea de Alcalá que destaca o tema do suposto desconhecimento do Paraguai e de sua literatura, há um capítulo intitulado La narrativa paraguaya desde 1960 a 1970 que coleta as principais produçóes do período e, novamente volta a aparecer o tema do Paraguai como incógnita. Agora, a referência lembra uma passagem de Halley Mora que polemiza com Roa Bastos ao discordar da mediterraneidade do país, demonstra as crescentes mudanças em processo no Paraguai que eliminam a ideia de mediterraneidade e, com esperança, conclui: 
Acaso el país se esté al fin restableciendo de la caída mortal de 1870. La cura total del traumatismo secular hará que el Paraguay deje de ser la patria absorta en su pasado, que fue hasta hace poco. Su literatura, entonces, podrá inspirarse, sin inhibiciones, con libertad creadora, en una realidad rica de valores humanos. (RODRÍGUEZ ALCALÁ, 1987, p. 75.)

Há um contraste de opiniōes em torno da presença/ausência da literatura imbuído na própria presença/ausência do país nos cenários continentais e internacionais. Escritores como Josefina Plá e a crítica Teresa Mendez Faith também reforçam a perspectiva da mediterraneidade do país indicada por Roa Bastos ${ }^{5}$. Rodríguez Alcalá, no entanto, năo necessariamente é contra tal perspectiva, somente se a ela está apoiada na ideia da năo existência de uma literatura paraguaia. Ou seja, o autor năo chega a pronunciar-se sobre o desconhecimento da literatura paraguaia em âmbito regional ou mundial, o que faz é defender que existe tal literatura, seja em seus artigos e polémicas como as travadas com o artigo de Luis Alberto Sánchez, seja pela construçâo de uma história da literatura paraguaia que procura dar difusâo e legitimidade à literatura de seu país. Desse modo, podemos inferir que, há uma literatura paraguaia, mas năo há um conhecimento regional ou internacional desta literatura. O que encontra-se ausente, portanto, é a crítica.

Neste aspecto, o crítico volta a distanciar-se de Roa Bastos e consequentemente, como é possível observar na análise de Carla Daniela Benizs, do pensamento de um dos importantes críticos da América Latina daquele momento, Ángel Rama. Para a autora (2021), Roa Bastos seguia o projeto do crítico uruguaio para quem a crítica constituiria a literatura em sua realizaçâo completa. Benizs parte de palavras de Roa Bastos na imprensa que diz: "nos falta en literatura una producción crítica específica. Esta falta está denotando, una vez más, las carencias de nuestra producción literaria, puesto que a una literatura en su madurez y plenitud corresponde siempre una crítica de igual magnitud" (Última hora, 17/10/1989 apud BENIZS, 2021).

A perspectiva de Rodríguez Alcalá acaba por demarcar esta diferença entre crítica e literatura uma vez que tende a reforçar a hipótese da presença da literatura versus ausência da crítica. Talvez pelo fato de que haja outro crítico literário no Paraguai, em seu tempo, que tenha obtido reconhecimento como ele sobre trabalhos em torno da literatura paraguaia e da literatura latino-americana. Além disso, trata-se de uma crítica elaborada no exterior que denuncia a dificuldade de existência e subsistência de críticos no próprio país. Assim, há uma dualidade interessante posta nesta cena no trabalho do autor: Rodríguez Alcalá denuncia as dificuldades da constituiçâo do próprio campo literário interno ao país, pois ele tem que contar com uma parte importante de tal campo, como a sua própria produçăo crítica, fora de seu território. Mas, ao mesmo tempo, trata-se de um importante trabalho de divulgaçâo da literatura paraguaia no exterior, tăo importante quanto o dos centros metropolitanos latino-americanos de produçăo cultural e intelectual, como Buenos Aires, para a divulgaçăo da literatura paraguaia para além de suas fronteiras. Assim, das três principais instâncias pensadas

5 O escritor Damián Cabrera mapeia o uso da metáfora da ilha na literatura do Paraguai em sua dissertaçáo de mestrado O Paraguai insular: a metáfora da ilha e movimentos insulares (2016). Ali a discussáo náo passa necessariamente pela existência ou náo de uma literatura no país e sim sobre sua situaçâo de isolamento, sua mediterraneidade e seu consequente desconhecimento. 
por Bourdieu desde a Europa como relevantes ao processo de autonomizaçăo da vida intelectual e artística, é neste terceiro, a instância de difusáo na qual se encontra o trabalho de Hugo Rodríguez Alcalá aqui considerado. Trata-se do cumprimento de um papel importante, construído fora do Paraguai já que năo foi dado ao crítico, necessariamente, a possibilidade de fazê-lo desde de seu lugar de origem.

O caminho tomado pelo crítico é o de muitos intelectuais, artistas e escritores que diante de dificuldades de manter seus trabalhos, devido a instabilidades sociais e políticas comuns aos países latino-americanos, se autoexilam. No Paraguai há toda uma literatura do exílio, na qual encontramos, entre outros, Rubén Bareiro Saguier e o próprio Roa Bastos. E, vale lembrar que, assim como a produçāo literária e crítica de Rodríguez Alcalá, esta também pode ser considerada uma literatura ausente de seu próprio país, apesar de existente.

Edward Said (2005), a partir do estudo de alguns intelectuais exilados, os separa entre aqueles que săo eternamente exilados, que năo se conformam à nova vida, ou seja, os "dissonantes", e aqueles que se adaptam a esta condiçâo de vida, os "consonantes". O modelo do intelectual exilado é normalmente identificado com os dissonantes, conforme Said, pois é o que nunca encontra-se plenamente. Mas, o consoante também é um exilado. Pode-se inferir, com base nestes tipos, que năo há em torno de Rodríguez Alcalá a aura de um intelectual exilado, de um intelectual dissonante que se identifica através desta característica, apesar de que Augusto Roa Bastos (apud Celia Correas de Zapata, 1996, p, 17) o considera junto a Heriberto Fernández e Rubén Bareiro Saguier como membros da "tríade de los nostálgicos de la tierra perdida". Mas, Roa Bastos se refere à produçāo poética de Hugo Rodríguez Alcalá realizada nos Estados Unidos. É nela que se manifesta de maneira mais veemente os sentimentos com relaçăo a ausência de sua terra natal ${ }^{6}$.

O exílio, ainda segundo Said, "significa que vamos estar sempre à margem e o que fazemos enquanto intelectuais tem de ser inventado porque năo podemos seguir um caminho prescrito." (SAID, 2005, p.69) Com isto talvez se explique o fato de nâo vermos em Alcalá esta identificaçăo de exilado, de nâo encontrarmos referências a sua retirada do país em seus textos críticos. Esta nâo identificaçăo pode ter tornado mais fácil a adaptaçăo e principalmente o desenvolvimento do trabalho que se propôs a fazer, a invençăo do seu próprio caminho. Ao năo se definir como um exilado também nâo se exigiu dele posiçôes políticas claras em torno do que acontecia em seu país de origem, seja no momento em que saiu, seja posteriormente. Como já foi dito, apesar de dedicar um capítulo de sua história da literatura à ditadura de Francia, nada aparece sobre a ditadura de Alfredo Stroessner que praticamente coincidiu com o período em que o crítico viveu nos Estados Unidos. Para Alcalá parece ter sido necessário o silêncio, necessária a aparente consonância com sua situaçăo de exilado para que pudesse haver seu necessário trabalho.

$6 \quad$ O tema do exílio na poesia de Hugo Rodríguez Alcalá pode ser apreciado em Palabras en los días, livro de poemas de 1972. 


\section{REFERÊNCIAS}

BENISZ, Carla Daniela. La “literatura ausente": Augusto Roa Bastos y las polémicas del Paraguay post-stronista $2^{a}$ ed. Buenos Aires: SB, 2018 (Libro digital EPUB - Colección Paraguay Contemporáneo)

. Ausencias y vindicaciones de la crítica en la literatura paraguaya. El nacional. 28 de março de 2021. Disponível em: https://www.elnacional.com.py/cultura/2021/03/28/ ausencias-y-vindicaciones-de-la-critica-en-la-literatura-paraguaya/. Acesso em: 03 de abril de 2021.

BOURDIEU, Pierre. A economia das trocas simbólicas. Săo Paulo: Perspectiva, 1992.

CABRERA, Damián. 0 Paraguai insular: a metáfora da ilha e movimentos insulares. Dissertaçăo (Mestrado em Estudos Culturais) Escola de Artes, Ciências e Humanidades,Universidade de Săo Paulo, São Paulo, 2016.

COMPAGNON, Antoine. A literatura. In: 0 demônio da teoria: literatura e senso comum. Trad. Cleonice Paes Mouráo e Consuelo Fortes Santiago. Belo Horizonte: Ed. UFMG, 2001, p. 29-46.

CORREAS DE ZAPATA, Celia. Hugo Rodríguez-Alcalá: poeta del exilio. Papeles de Son Armadans n. ${ }^{\circ}$ 248, 1976.

FOSTER, David William. Hugo Rodriguez-Alcalá. Narrativa hispanoamericana, GuiraldesCarpentier, Roa Bastos-Rulfo. Revista Iberoamericana, 1975. (resenha)

GIES, David T. El hispanismo que viene: Estados Unidos y Canadá. Arbor, CLXVIII, 664, Abril 2001, p. 493-511. Disponível em: http://arbor.revistas.csic.es/index.php/arbor/ article/view/859/866. Acesso em 23 de fevereiro de 2021.

MARCOS, Juan Manuel. La poética de Hugo Rodríguez Alcalá: técnica y estilo. Assunçăo: Arandură, 1997.

MENDEZ-FAITH, Tereza. Paraguay: novela y exílio. Somerville, N.J. : SLUSA, 1985.

RODRÍGUEZ ALCALÁ, Hugo Rodríguez. Historia de la literatura paraguaya. Assunçăo: Colegio San Jose, 1971.

La incógnita del Paraguay y otros ensayos. Assunçâo: Arte Nuevo Editores, 1987.

Quince ensayos. Assunçâo: Criterio Ediciones, 1987.

SAID, Edward. Exilio intelectual: expatriados e marginais. In: Representaçōes do intelectual: as conferências Reith de 1993. Trad. Milton Hatoum. Sáo Paulo: Cia das Letras, 2005, p. 55-70. 